\title{
ESTATÍSTICA E PROBABILIDADE NOS ANOS INICIAIS: 0 LÚDICO COMO FERRAMENTA DE ENSINO E APRENDIZAGEM NO UNIVERSO INFANTIL
}

\author{
STATISTICS AND PROBABILITY IN THE INITIAL YEARS: \\ DOMINGOS ANTONIO LOPES ${ }^{1}$ \\ CRISTIANA ANDRADE POFFAL² \\ CINTHYA MARIA SCHNEIDER MENEGHETTI
}

THE LUDIC AS A TOOL FOR LEARNING AND EDUCATION IN THE CHILDREN'S UNIVERSE

\section{RESUMO}

0 artigo traz o planejamento, aplicação e resultados de atividades aplicadas numa turma de $3^{\circ}$ ano do Ensino Fundamental, com relação a unidade temática, Estatística e Probabilidade, conforme prevê a Base Nacional Comum Curricular. Tendo por objetivo, além da percepção das possíveis competências que podem surgir, instigar a ideia de acaso em situações do cotidiano, trazendo pela primeira vez o conceito de espaço amostral, permitindo a coleta, interpretação e representação de dados e variáveis em tabelas e em gráficos. A importância do estudo dessa unidade foi dividida em três encontros: apresentação de conceitos fundamentais estocásticos, o Jogo de dados e o questionário "Do que você tem medo?". Em um universo de letramento e alfabetização matemática, o lúdico se apresenta como uma excelente ferramenta metodológica no despertar de um conteúdo tão distante a ao mesmo tempo tão próximo do cotidiano.

Palavras-chave: Probabilidade. Estatística. Lúdico. Anos Iniciais. Educação Básica.

\section{ABSTRACT}

The paper presents the planning, application and results of activities applied in a 3rd year class of Elementary School, regarding the thematic unit, Statistics and Probability, as foreseen by the Common National Curricular Base. Having as objective, beyond the perception of the possible competences that may arise, to stimulate the idea of chance in daily situations, introducing for the first time the concept of sample space, allowing the collection, interpretation and representation of data and variables in tables and graphs. The importance of the study of this unit was divided into three meetings: presentation of stochastic fundamental concepts, the Dice Game and the "What are you afraid of?" questionnaire. In a universe of mathematics literacy, the ludic presents itself as an excellent methodological tool in the awakening of a content so distant yet so close to everyday life.

Keywords: Probability. Statistics. Ludic. Early Years. Basic Education.

\footnotetext{
1 Mestre em Matemática pelo PROFMAT. SESI/RS e Prefeitura Municipal da cidade do Rio Grande. E-mail: domingoschaplin@hotmail.com. Orcid: https://orcid.org/0000-0002-2640-0120

2 Dra. em Engenharia Mecânica. Instituto de Matemática, Estatística e Física - FURG. E-mail: cristianaandrade@furg.com. Orcid: https://orcid. org/0000-0002-0108-7051

3 Dra. Em Matemática. Instituto de Matemática, Estatística e Física - FURG. E-mail: cinthyaschneider@furg.br. Orcid: https://orcid.org/ 0000-0002-8750-2462
} 


\section{INTRODUÇÃO}

A Base Nacional Comum Curricular (BNCC) (BRASIL, 2017) reforça a proposta dos Parâmetros Curriculares Nacionais (BRASIL, 1997) e traz na sua essência as estratégias que podem ser desenvolvidas para que 0 aluno em todas as etapas e modalidades da Educação Básica possa ter uma progressão nas suas aprendizagens essenciais, através das competências que surgirão ao longo da sua formação pedagógica. Nesse novo fazer, a BNCC reforça o papel protagonista do aluno e busca um cidadão autônomo, criativo e crítico, tendo a oportunidade de argumentar e questionar fatos, num processo contínuo de comunicação.

Para descrever sobre esse artigo, importante trazer a fala de Cazorla, Magina, Gitirana e Guimarães (2017) afirmando segundo a proposta de Brasil(1997) constituindo-se num grande avanço para 0 ensino de Estatística e Probabilidade na Educação Básica. Suas diretrizes têm como intenção 0 desenvolvimento do pensamento estatístico que provavelmente dará às novas gerações, uma formação básica sólida em Estatística, contribuindo na formação de cidadãos críticos e conscientes.

[...]é preciso auxiliar e incentivar os indivíduos, especialmente as crianças, no desenvolvimento do pensamento científico. Propiciar situações para que ela saiba, por exemplo, identificar um problema, elaborar questões, levantar hipóteses e testar sua validade; escolher que dados coletar e como fazê-lo; saber ainda como organizá-los e interpretá-los, estando apta a lançar mão de conceitos e procedimentos estatísticos para interpretar corretamente os dados colhidos em sua pesquisa ou na pesquisa de outrem. (CAZORLA et al., 2017, p. 11)

Esse pensamento atribui significado à intervenção proposta nesse trabalho, que consiste em duas atividades realizadas em três encontros com uma turma do $3^{\circ}$ ano dos Anos Iniciais do Ensino Fundamental, em uma Escola Municipal, com o tema Estatística e Probabilidade, de acordo com os seus objetos e habilidades de conhecimento descritos na BNCC (BRASIL, 2017). As atividades têm por objetivo: instigar, nesses estudantes, a ideia de acaso em situações do cotidiano, trazendo pela primeira vez 0 conceito de espaço amostral, além de permitir a coleta, leitura, interpretação, classificação e representação de dados e variáveis em tabelas de dupla entrada e em gráficos. As atividades "Jogo dos Dados" e "Do que você tem medo?" despertaram, de forma lúdica, um novo olhar para 0 conteúdo de matemática. A proposta dessas atividades pode transitar tanto no Ensino Fundamental quanto no Médio, com as devidas adequações que forem necessárias, propondo, inclusive, uma transversalidade e interdisciplinaridade.

\section{A IMPORTÂNCIA DO ENSINO DE ESTATÍSTICA E PROBABILIDADE NOS ANOS INICIAIS}

Todas as unidades temáticas descritas na BNCC (BRASIL, 2017) são apresentadas em consonância com os objetos e habilidades de conhecimento, a fim de promover as suas competências específicas. Mas como verificar se, de fato, foram desenvolvidas? Segundo Freitas, Bertolucci, Roveda e Silva (2019) fica a cargo do professor entender "como" desenvolver uma competência a partir dos objetos de conhecimento e habilidades elencadas no documento. Em paralelo a isso, é preciso compreender o protagonismo do aluno nas questões de ser "responsável" por sua aprendizagem. A afirmação do 
autor promove um novo fazer na sala de aula, com metodologias que de fato possam desenvolver as habilidades de conhecimento e, assim, as competências previstas, além de permitir que 0 aluno assuma o papel de protagonista. As atividades "Jogo de Dados" e "Do que você tem medo?", aplicadas na unidade temática Estatística e Probabilidade, buscam atender algumas competências, conforme sugere Freitas et al. (2019).

A estatística é uma disciplina metodológica. Não existe para si, mas para oferecer a outros campos de estudo um conjunto coerente de ideias e ferramentas para lidar com dados. A necessidade de uma disciplina surge da onipresença da variabilidade. (COBB; MOORE, $1997^{4}$ apud LOPES, 2012, p. 167)

A citação traz 0 quanto 0 conteúdo de Estatística e Probabilidade é de extrema importância e relevância e transita por várias áreas de conhecimento, reforçando 0 quanto é significativo 0 seu estudo. Visto, antes da implantação da BNCC (BRASIL, 2017), como um tema transversal, na maioria das vezes era deixado de lado pelo currículo. Atualmente, como uma unidade temática dentro da área de conhecimento de matemática, consolida-se como um tema indispensável em todos os anos da Educação Básica.

A Educação Estatística está centrada no estudo da compreensão de como as pessoas aprendem Estatística envolvendo os aspectos cognitivos e afetivos e o desenvolvimento de abordagens didáticas e de materiais de ensino. Para isso, a Educação Estatística precisa da contribuição da Educação Matemática, da Psicologia, da Pedagogia, da Filosofia, da Matemática, além da própria Estatística. (CAZORLA et al., 2017, p. 15)

Essa compreensão atribui significado à abordagem didática e aos materiais, que ao serem escolhidos para trabalhar essa unidade temática, podem ser instrumentos efetivos para que as pessoas compreendam Estatística e Probabilidade. As autoras trazem também os aspectos cognitivos e afetivos, essenciais nesse processo de ensino e aprendizagem.

0 trabalho com Estatística na escola propicia 0 desenvolvimento do pensamento estatístico, a vivência de um trabalho interdisciplinar e possibilita abordar temas transversais. [...] o pensamento estatístico amplia as formas de pensar valorizando o mundo das incertezas. (CAZORLA et al., 2017, p. 17)

As autoras reforçam 0 quanto essa unidade tem uma característica interdisciplinar e pode transitar por outras ciências, conferindo significado a conteúdos que muitas vezes acabam sendo vistos pelos alunos sem aplicabilidade. Também reforçam que nem sempre um resultado esperado por todos, pode ocorrer de fato, aumentando o número de possibilidades de ocorrência de um evento.

É importante salientar que as crianças nos Anos Iniciais estão em fase de letramento e alfabetização matemática. Nesse universo de aprendizagem, a descoberta pelo novo e como entender todo esse conhecimento, 0 aluno usa o seu potencial criativo, argumentativo, crítico, comunicativo, entre outros, tornando 0 ambiente da sala de aula muito rico para todos, docentes e alunos. Nesse processo de aprender, a Estatística e Probabilidade torna-se um tema visto como uma ciência do cotidiano.

Na sequência, serão apresentados o planejamento e os materiais utilizados nas atividades com 
os alunos do $3^{\mathrm{a}}$ ano dos Anos Iniciais, buscando atender às premissas da BNCC e as reflexões dos autores já citados.

\section{PLANEJANDO ATIVIDADES ADEQUADAS À BNCC E À REALIDADE ESCOLAR}

A elaboração das atividades que serão aplicadas na turma, busca estar adequada ao que está proposto à unidade temática Estatística e Probabilidade para uma turma de $3^{\circ}$ ano da Educação Básica. Conforme Bernstein ${ }^{5}$ (1996, apud Freitas, Silva, Roveda e Marques, 2018) temos diferentes discursos pedagógicos que norteiam os currículos. 0 que 0 autor nos traz, é que nem sempre 0 que foi proposto pelo discurso da construção da BNCC (BRASIL, 2017) será aplicado de forma integral na sala de aula pelo docente, pois o texto perpassa pelo discurso do Projeto Político Pedagógico e pela realidade da escola onde está inserida, incorporando o discurso da comunidade escolar. Sendo assim, as atividades foram adaptadas para o discurso da escola e da turma onde serão aplicadas.

No primeiro encontro, serão abordados com os estudantes os conceitos fundamentais de Probabilidade e Estatística, especialmente População e Amostra, além da ideia do acaso em situações do cotidiano e como descrever o espaço amostral. Para que os alunos compreendam os conceitos, População e Amostra, e assim se sintam pertencentes a essas definições, será utilizado o recurso do Google Maps ${ }^{\circledR}$. A proposta é, a partir do mapa do Estado do Rio Grande do Sul, com as devidas aproximações, chegar ao espaço da sala de aula da turma.

Através de ferramentas tecnológicas, reforçada pela BNCC (BRASIL, 2017), com 0 uso ou não do laboratório de informática na escola, os alunos terão a oportunidade de visualizar o mapa do Estado através do Google Maps ${ }^{\circledR}$. Nesse momento, os alunos identificarão o quanto 0 seu Estado é enorme, constituído de muitos habitantes, portanto, uma grande população de alunos do $3^{\circ}$ ano, em escolas públicas e particulares. É feito o primeiro refinamento dessa população, pois escolheremos a cidade onde residem como sendo uma amostra. Enquanto observam o mapa da sua cidade, também irão identificar que se tem uma grande população de alunos, portanto se faz um segundo refinamento, escolhendo 0 bairro em que residem como uma amostra. Um novo refinamento e o bairro passa a ser uma população e a escola torna-se uma amostra. Finalmente, a sala de aula torna-se uma amostra da população de alunos do $3^{\circ}$ ano do Estado.

Para entenderem o termo "acaso" e "espaço amostral" serão apresentados exemplos de situações aleatórias, arbitrárias, ao acaso e imprevisíveis, para discutir em aula: Se eu jogar esta moeda para 0 alto, ela irá cair?; Parece que vai chover hoje!; Vou fazer esta cadeira desintegrar-se; É possível que meu time ganhe o próximo campeonato.

0 primeiro encontro termina com a apresentação aos alunos dos tipos de gráficos existentes, dando mais importância ao gráfico de colunas, previsto nas habilidades de conhecimento na BNCC (BRASIL, 2017) do $3^{\circ}$ ano e aos programas computacionais que permitem a elaboração de gráficos a partir da construção de tabelas.

Ao apresentar exemplos de tabelas a partir de programas computacionais e convertê-las em gráficos, pretende-se que os alunos compreendam que essa conversão está focada na teoria das representações semióticas, de Duval. Segundo Duval (2003), as representações semióticas são elaborações produzidas pela aplicação dos signos pertencentes a um sistema de representações que possui intervenções próprias de signos e funcionamento. Essas representações são essenciais à atividade cognitiva do pensamento e podem mostrar um mesmo objeto de diversas 5 BERNSTEIN, B. A estruturação do discurso pedagógico: classe, códigos e controle. Petrópolis: Vozes, 1996. 
formas. Dessa maneira, a conversão de uma tabela em gráfico permite facilitar a compreensão de dados.

Segundo Lopes (2012), as crianças têm direito a um espaço educativo em que sejam estimuladas a expressar seu pensamento utilizando linguagem; precisam inventar e narrar suas próprias histórias para os colegas. 0 que a autora nos traz será fundamental na aplicação das duas atividades, pois segundo Lopes (2012) faz-se necessário desenvolver uma atitude de respeito aos saberes que a criança traz à escola, adquiridos em seu meio cultural, o que, muitas vezes, envolve a discussão de temas como: a cidade em que mora, o país em que vive, o meio ambiente, a poluição dos rios e dos mares, entre outros. Isto é, assuntos do seu cotidiano.

As atividades propostas precisam instigar o pensamento criativo, investigativo e imaginário, pois segundo Lopes (2012) a criança lê o mundo e questiona o que vê. Precisamos de espaços educativos nos quais ela expresse suas dúvidas e socialize suas hipóteses e respostas. Dessa forma, acredita-se que as atividades propostas possam provocar, na sua dinâmica, 0 surgimento da hipótese do porquê 0 $n^{0} 7$ não aparece no jogo dos dados em todas as possibilidades, a hipótese do medo das meninas ser maior que dos meninos ou vice-versa e, assim, socializem suas respostas a essas questões.

Para que os estudantes possam entender 0 conceito de eventos aleatórios e os resultados possíveis, estimando os que têm maiores ou menores chances de ocorrência, propõe-se no segundo encontro a $1^{\mathrm{a}}$ atividade "Jogo de dados" com o lançamento de 03 dados. Os dados podem ser construídos usando modelos de dobradura, nas dimensões que o docente definir e conforme ilustra a Figura 1 ou, se preferir, pode trazer os dados prontos.

Figura 1 - Modelo em cartona para construção de um dado

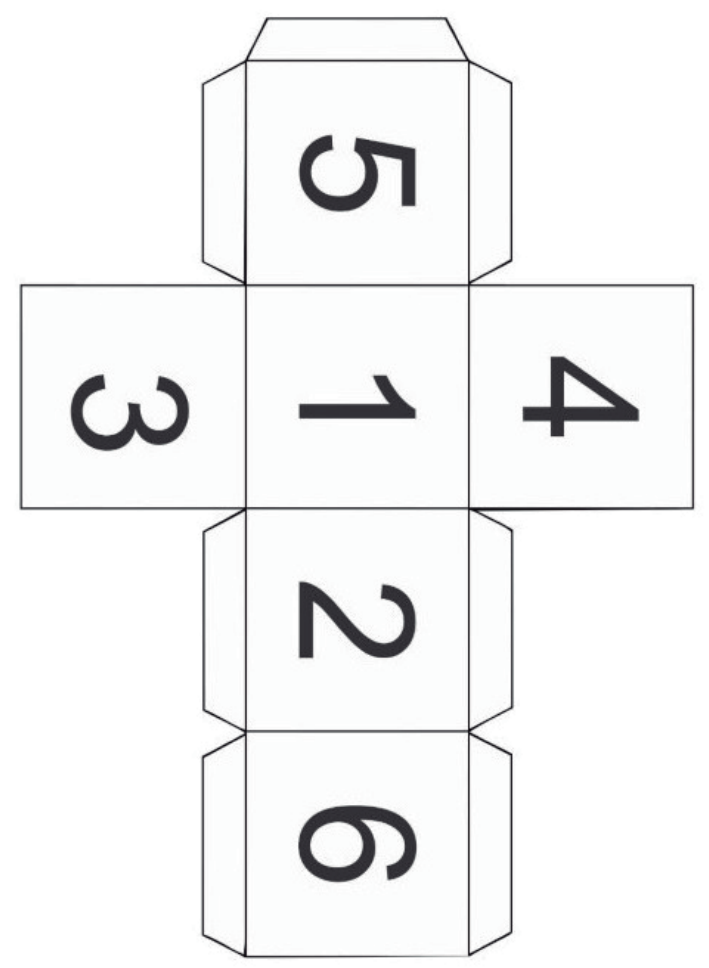

Fonte: https://www.artesanatopassoapassoja.com.br/molde-de-dado/ 
A construção do dado pode possibilitar outras aprendizagens, como da unidade de conhecimento, geometria. Pode ser trabalhada a forma geométrica dos lados do dado, o número de lados, verificando com os alunos que todos os lados são iguais, que a linha que une os lados são as arestas e, quando juntos, formam a superfície espacial denominada cubo.

A atividade "Jogo de dados" propõe ao aluno que encontre, com o lançamento dos dados, 0 número sete (7) como resultado do evento. Inicialmente será lançado apenas um dado e os alunos serão questionados, se o resultado esperado $\left(n^{0} 7\right)$ tem chance de ocorrência no evento. Na sequência, serão lançados dois dados e, após três dados, um de cada vez, vamos solicitar aos alunos se é possível encontrar o número sete. Sugere-se ao docente que permita que os alunos façam as suas conjecturas. Segundo a BNCC (BRASIL, 2017), esse é o momento de perceber se algumas competências irão surgir através do exercício da curiosidade intelectual, recorrendo à abordagem própria das Ciências, incluindo a investigação, a reflexão, a análise crítica, a imaginação e a criatividade, investigando causas, elaborando e testando hipóteses, formulando e resolvendo problemas e criando soluções com base nos conhecimentos das diferentes áreas.

Por meio de sua curiosidade a criança é levada a questionar, investigar e descobrir coisas novas. Ela age de forma similar à investigação científica ao levantar questionamentos a partir de suas observações. Cabe a nós, professores da escola, aproveitar a curiosidade infantil como um primeiro elemento na condução de uma pesquisa estatística, a qual pode ajudar na compreensão de aspectos do mundo que a cerca. Aguçar a identificação das dúvidas tem, portanto, um papel fundamental no desenvolvimento do pensamento estatístico das crianças. (CAZORLA et al., 2017, p. 20)

A partir da citação das autoras, a atividade proposta em sala de aula será capaz de promover ou não esse pensamento estatístico. Portanto, os dados ao serem lançados instigarão a curiosidade do grupo em busca do resultado do número sete, construindo arranjos e permutações entre os dados, para que possam chegar ao resultado esperado, tendo menor ou maior chance de ocorrer. A Tabela 1 apresenta as possibilidades de arranjos dos dados que os alunos poderão encontrar.

Tabela 1 - Número de possibilidades do surgimento do $\mathrm{n}^{0} 7$ com o lançamento dos dados.

\begin{tabular}{ccc}
\hline Nenhuma chance de ocorrência & Menor chance de ocorrência & Maior chance de ocorrência \\
\hline 01 dado & 02 dados & 03 dados \\
$1+6 / 6+1$ & $1+1+5 / 5+1+1$ \\
$2+5 / 5+2$ & $1+2+4 / 4+2+1$ \\
$3+4 / 4+3$ & $1+3+3 / 3+3+1$ \\
& & $1+4+2 / 2+4+1$ \\
& & $1+5+1$ \\
& & $2+1+4 / 4+1+2$ \\
& & $2+3+3+2+2$ \\
Zero possibilidades & & $3+1+3$ \\
\hline
\end{tabular}

Fonte: Construção do autor. 
Após o lançamento dos dados, desenvolva com os alunos o conceito de espaço amostral para 0 resultado esperado do $n^{0} 7$. Segundo Morgado \& Carvalho (2015), espaço amostral é o conjunto de todos os resultados possíveis de uma experiência aleatória.

A educação matemática, ao se inserir nesse contexto da infância, deve estar pautada na ludicidade e na exploração do universo infantil. Deve favorecer a formação de crianças criativas, críticas e aptas a ler e compreender seu cotidiano infantil, que é caracterizado por sua imaginação e por seus questionamentos constantes. (LOPES, 2012, p. 166)

A citação da autora atribui significado à próxima atividade, pois levanta questões sobre 0 que a criança tem medo indo ao encontro do imaginário infantil e, com certeza, de muitos questionamentos.

No terceiro dia, serão retomados os conceitos de população e amostra, pois a partir da realização da $2^{\mathrm{a}}$ atividade "Do que você tem medo?", um questionário baseado na metodologia sugerida por Santos (2018) e que aparece como sugestão em Cazorla et al. (2017), fornecerá os dados necessários que responderão à proposta da $2^{\mathrm{a}}$ atividade e serão denominados de variáveis. Essas variáveis representarão uma amostra da população de situações que descreveriam possíveis circunstâncias que provocariam medo ou não no universo infantil.

Como forma de organização das variáveis, será utilizada a teoria de Representações Semióticas de Duval (2003), referenciada por Colombo, Buehring e Moretti (2009) em relação à aprendizagem matemática, na teoria dos registros de representação semiótica, dando o seguinte aporte:

É essencial que na atividade matemática de aprendizagem seja possível mobilizar muitos registros de representação semiótica no decorrer de um mesmo passo. A hipótese de aprendizagem desse autor baseia-se na articulação dos registros de representação semiótica do objeto matemático em estudo. 0 autor ainda traz que as tarefas devem ser implementadas de tal modo que 0 uso da hipótese de aprendizagem seja possível. (DUVAL ${ }^{6}, 2003$, p.92 apud COLOMBO et al., 2009)

Dessa forma, vamos converter essas variáveis obtidas dos questionários em tabela, e então, convertê-las numa representação gráfica que representarão uma amostra. Os dados, por serem extraídos pelos próprios alunos, são definidos como fonte primária, ressaltando que as variáveis do estudo serão gênero e tipo de medo. A Figura 2 exemplifica o modelo de questionário que será realizado com a turma. 
Figura 2 - Questionário da 2a atividade "Do que você tem medo?"

\begin{tabular}{|c|c|c|c|}
\hline \multicolumn{2}{|c|}{$\begin{array}{l}\text { Marque um " } \mathrm{x} \text { " no emoji que identifica se } \\
\text { você não tem ou tem medo. }\end{array}$} & & 6 \\
\hline \multicolumn{4}{|c|}{ 1. Você tem medo do Bicho Papão? } \\
\hline \multicolumn{4}{|c|}{ 2. Você tem medo de palhaço? } \\
\hline \multicolumn{4}{|c|}{ 3. Você tem medo de um elefante? } \\
\hline \multicolumn{4}{|c|}{$\begin{array}{l}\text { 4. E de um rato de laboratório, você tem } \\
\text { medo? }\end{array}$} \\
\hline \multicolumn{4}{|c|}{ 5. Você tem medo de altura? } \\
\hline \multicolumn{4}{|c|}{ 6. Você tem medo do escuro? } \\
\hline \multicolumn{4}{|c|}{ 7. Você tem medo de histórias de terror? } \\
\hline \multicolumn{4}{|c|}{$\begin{array}{l}\text { 8. E se for um filme de terror, você tem } \\
\text { medo? }\end{array}$} \\
\hline \multicolumn{4}{|c|}{ 9. Você tem medo de cobra e de aranha? } \\
\hline \multicolumn{4}{|c|}{$\begin{array}{l}\text { 10. Você tem medo de andar de } \\
\text { barco? }\end{array}$} \\
\hline \multicolumn{4}{|c|}{$\begin{array}{l}\text { 11. E de voar de avião, você tem } \\
\text { medo? }\end{array}$} \\
\hline \multicolumn{4}{|c|}{ 12. Você tem medo de pássaros? } \\
\hline \multicolumn{4}{|c|}{$\begin{array}{l}\text { 13. E se no lugar de pássaros, for } \\
\text { morcegos, você tem medo? }\end{array}$} \\
\hline \multicolumn{4}{|c|}{ 14. Você tem medo dos peixes? } \\
\hline \multicolumn{4}{|c|}{$\begin{array}{l}\text { 15. E se o peixe for um tubarão, você } \\
\text { tem medo? }\end{array}$} \\
\hline NÄO TEM MEDO & $\therefore$ & TEM MEDO & \\
\hline
\end{tabular}

Fonte: Construção do autor.

Divididos em grupos, cada aluno recebe o questionário proposto como mostra a Figura 2 e, individualmente, deverá responder às quinze perguntas. Com os questionários respondidos, chega 0 momento de compartilhar com o seu grupo a sua percepção do que tem medo ou não para, então, tabular os resultados. Segundo a BNCC (BRASIL, 2017), esse é o momento de argumentar com base em fatos, dados e informações confiáveis para formular, negociar e defender ideias, pontos de vista e decisões comuns. É mais uma competência acontecendo. A seguir, peça aos grupos que depois de compilados os dados, separem por gênero as respostas das 15 perguntas.

Com a compilação pronta pelos grupos, chega a hora de construir a tabela do grande grupo. Como sugestão, para ganhar tempo, o professor pode levar pronta a tabela (em papel a metro) e preenchê-la em aula, a partir da compilação dos dados dos questionários ou escolher o quadro da sala como recurso para essa etapa da atividade. Dessa forma, ganha tempo e pode trabalhar algumas informações importantes, tais como: Qual é o nome que podemos dar para a tabela? Qual é a fonte dos resultados? Quantos alunos há em aula? Quantas meninas há na sala? E meninos? A Figura 3 descreve um modelo da tabela a ser construída. Caso tenha optado pelo uso da tabela em papel a metro, fica como sugestão fixá-la em sala de aula, para que os alunos possam comparar as variáveis 
convertidas em tabela e na sequência da atividade, a tabela convertida em representação gráfica. Ao utilizar a tabela, por exemplo, o docente na primeira interrogação "Você tem medo do Bicho Papão?" vai preencher com o número de meninas que tem medo ou não tem medo, da mesma forma, o número de meninos que são indiferentes ao Bicho Papão e aqueles que não são.

Figura 3 - Modelo de uma tabela para compilação dos resultados da turma

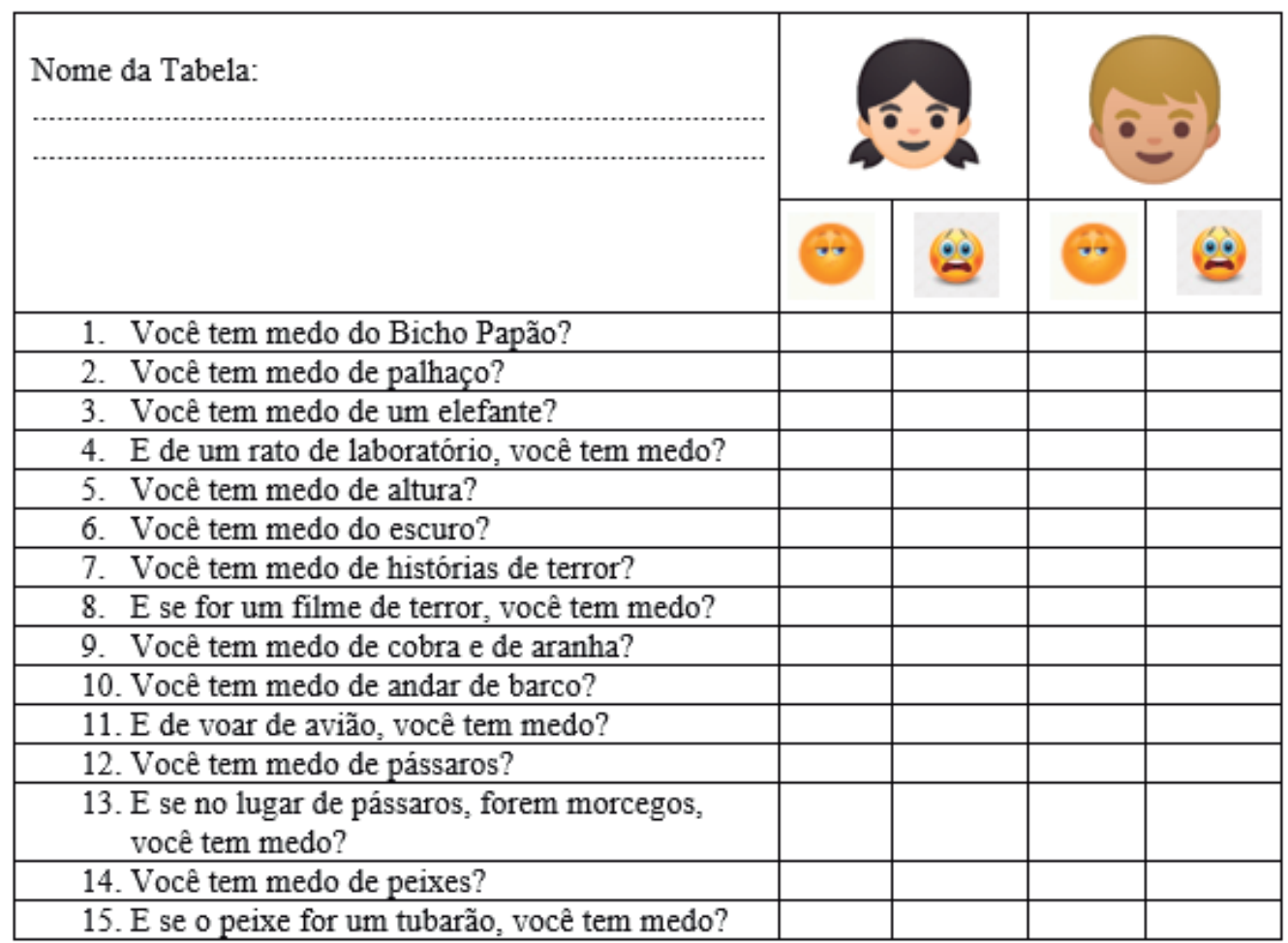

Fonte: Construção do autor.

0 docente pode solicitar que um representante de cada grupo apresente os resultados compilados para cada pergunta para que, assim, essas informações possam ser agregadas à tabela ou ao quadro, caso 0 docente tenha optado por essa ferramenta. Segundo a BNCC (BRASIL, 2017) é momento de valorizar a diversidade de saberes e vivências, apropriando-se de conhecimentos e experiências que the possibilitem entender as relações próprias do mundo do trabalho e fazer escolhas alinhadas ao exercício da cidadania, com liberdade, autonomia, consciência crítica e responsabilidade. Discuta e analise a tabela com os alunos: quantidade de linhas, de colunas, de células e quais informações elas trazem. É relevante também que o docente saiba, conforme Cazorla et al. (2017) que o gênero e os tipos de medo são variáveis qualitativas e, neste caso, ambas nominais, já que suas categorias não podem ser ordenadas, pois ter medo de fantasma não é maior, igual ou menor que ter medo de rato.

Com a tabela pronta, deve ser feita a sua conversão em dois gráficos de dupla entrada que serão construídos de forma distinta, a fim de facilitar a leitura, cada grupo construirá: 0 gráfico com as respostas "Não tem medo" e "Tem medo". No eixo horizontal (base do gráfico) ficam as perguntas, numeradas de 1 a 15, com objetivo de facilitar a visualização e não poluir 0 gráfico. Já 0 eixo vertical ilustra o número de meninas e meninos relacionado a cada pergunta. 
Nesse momento, é muito importante que o professor traga o conceito de escala, de uma forma bem simples, para que as informações do eixo vertical possam estar ajustadas aos resultados e as 15 perguntas distribuídas ao longo da base do gráfico. Para 0 eixo vertical do gráfico, sugere-se a utilização como escala a tabuada do número 2, com espaçamento de 2 em 2, já para 0 eixo horizontal, a largura poderá ser construída em cartolina, dois gráficos por grupo. 0 Gráfico 1 exemplifica a construção sugerida.

Gráfico 1 - Modelo dos gráficos que serão construídos pelos alunos

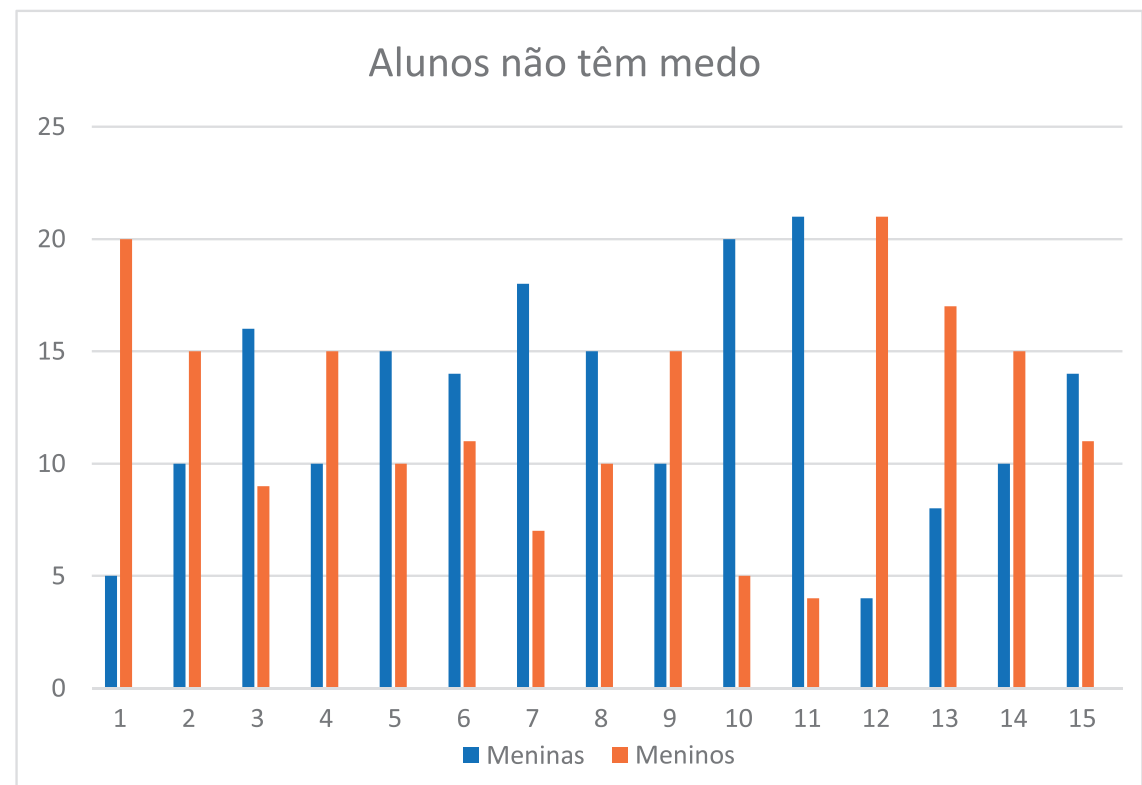

Fonte: Construção do autor.

0 preenchimento da tabela e a construção dos gráficos pelos grupos servem como uma ferramenta de avaliação do processo de ensino e aprendizagem, já que a progressão do conhecimento ocorre durante toda a evolução das atividades propostas, ampliando, dessa forma, suas práticas de linguagem e da experiência com situações diferentes do seu cotidiano.

[...] ao valorizar as situações lúdicas de aprendizagem, aponta para a necessária articulação com as experiências vivenciadas na Educação Infantil. Tal articulação precisa prever tanto a progressiva sistematização dessas experiências quanto 0 desenvolvimento, pelos alunos, de novas formas de relação com o mundo, novas possibilidades de ler e formular hipóteses sobre os fenômenos, de testá-las, de refutá-las, de elaborar conclusões, em uma atitude ativa na construção de conhecimentos. (BNCC, 2017, p. 9) 
A citação reforça a proposta das atividades, pois todos os encontros preveem a progressiva sistematização do desenvolvimento dos alunos através das práticas lúdicas, buscando promover uma atitude ativa na construção do conhecimento.

Na sequência, serão apresentados os resultados e discussões da aplicação das atividades.

\section{RESULTADOS E DISCUSSÃO DAS ATIVIDADES IN LOCO}

A turma em que foram aplicadas as atividades é constituída de 23 alunos, sendo 8 meninas e 15 meninos, com 03 alunos incluídos laudados: um aluno com Síndrome de Asperger (TEA), outro com Transtorno do Déficit de Atenção e hiperatividade (TDAH) e o terceiro possui Transtorno Global do desenvolvimento (TGD). 0 aluno com TGD não participou das atividades em aula, permaneceu somente 10 minutos e o restante do horário desenvolveu atividades na sala de recursos da escola.

Foi necessário que o responsável de cada aluno compreendesse a intervenção do conteúdo proposto na sala de aula e permitisse 0 uso das imagens dos alunos envolvidos e de suas atividades. Para isso, foi feito um documento intitulado Autorização para uso de imagem e obras escolares que foi entregue a cada responsável, retornando assinado pelo mesmo.

Segundo Pimenta (2018), a Síndrome de Asperger é um transtorno neurobiológico enquadrado na categoria Transtornos do Neurodesenvolvimento, de acordo com o Manual Diagnóstico e Estatístico de Transtornos Mentais (DSM-V), afeta a forma como as pessoas percebem o mundo e interagem com outras pessoas. Trata-se de um dos perfis ou espectro de autismo, o chamado Transtorno do Espectro Autista (TEA). Segundo a Associação Brasileira do Déficit de Atenção ABDA (2018), o TDAH é um transtorno neurobiológico, de causas genéticas que aparece na infância e frequentemente acompanha 0 indivíduo por toda a sua vida. Ele se caracteriza por sintomas de desatenção, inquietude e impulsividade. Ele é chamado, às vezes, de DDA (Distúrbio do Déficit de Atenção). Segundo Nadal (2012), os TGD são distúrbios nas interações sociais recíprocas que costumam manifestar-se nos primeiros cinco anos de vida. Caracterizam-se pelos padrões de comunicação estereotipados e repetitivos, assim como pelo estreitamento nos interesses e nas atividades. Os TGD englobam os diferentes transtornos do espectro autista, as psicoses infantis, a Síndrome de Asperger, a Síndrome de Kanner e a Síndrome de Rett.

0 aluno com TEA participou e interagiu em todas as atividades propostas, evidenciando um perfil autoritário, mas em todas as atividades estava incluso nos grupos. 0 aluno com TDAH participou ativamente de todas as atividades, perguntando bastante durante a realização da oficina.

No primeiro encontro com a turma foram apresentados conceitos iniciais de estatística, como população e amostra, utilizando-se o recurso do Google Maps ${ }^{\circledR}$ para fazer a relação de população e amostra, concluindo com os alunos, que a turma do $3^{\circ}$ ano é uma amostra da população dos $3^{\circ}$ anos do Rio Grande do Sul. Também se enfatizou com os alunos que a palavra população, em estatística, não está ligada somente a pessoas, pode ser uma população de animais específicos, cartas, figuras, selos, entre outros. A Figura 4 ilustra o primeiro encontro com a turma, onde são apresentados os conceitos de população, amostra, variáveis aleatórias e exemplos de população, além dos gráficos existentes, focando nos gráficos de colunas de simples e dupla entrada previsto nas habilidades de conhecimento da BNCC (BRASIL, 2017). 
Figura 4 - Primeiro momento de interação com a turma.

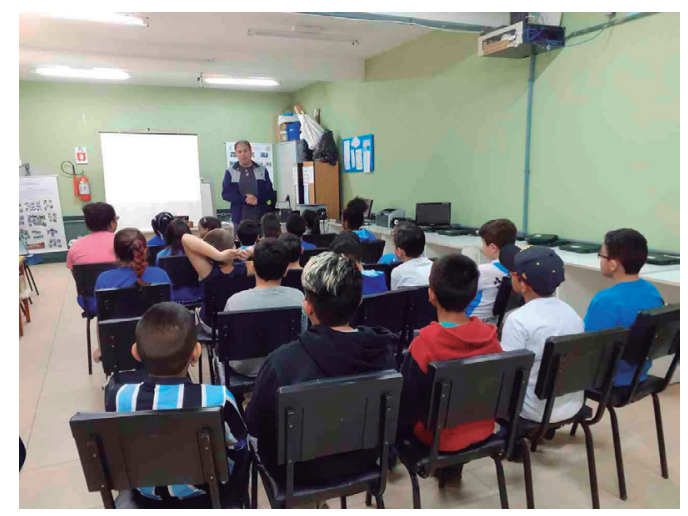

Fonte: Próprio autor.

Nesse primeiro encontro também foram apresentados alguns tipos de histogramas (gráfico de coluna simples e dupla entrada). Na sequência, foi mostrada a sua construção através de programas que possibilitam a conversão dos dados em gráficos após a construção da tabela, apenas para conhecimento. A Figura 5 ilustra 0 momento de interação e a possibilidade da inserção das tecnologias como recurso pedagógico.

Figura 5 - 0 uso das tecnologias na construção de tabelas e gráficos.

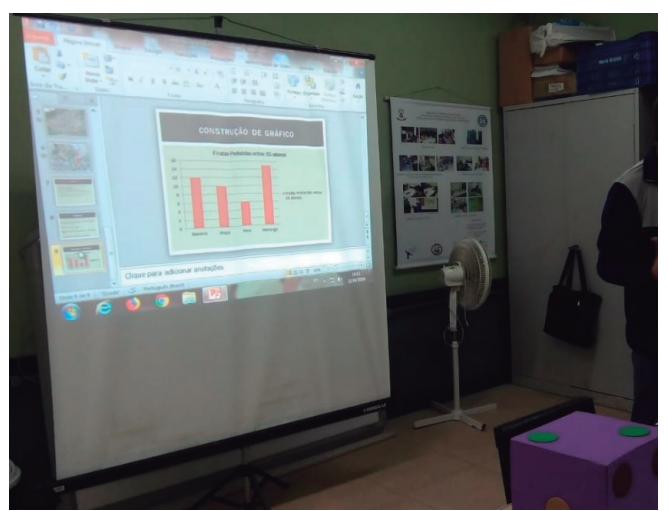

Fonte: Próprio autor.

A oportunidade da utilização do laboratório de informática favoreceu a inserção do aluno no universo das Tecnologias de Informação ( $\mathrm{TI}$ ) para que, dessa forma, compreendesse que os recursos tecnológicos não são apenas as redes sociais, mas que existem outras possibilidades da sua utilização, buscando tornar o aluno crítico, criativo e ético.

A proposta de utilizar os computadores no processo educativo desde as séries iniciais é de Papert7, pois segundo sua proposta o computador iria "ampliar a escola", revolucionar a educação e reformular a mente das crianças. Sua linguagem de 
programação, projetada especialmente para crianças, deveria provocar o estímulo para essa revolução. (JUNIOR, 2012)

A citação acima descreve o processo de descoberta que a criança, nas séries iniciais, se estimulada, desenvolve de forma significativa sua questão cognitiva, física e mental, indo ao encontro do que propõe Brasil (2017) com relação ao desenvolvimento da competência de exercitar a curiosidade intelectual e recorrer à abordagem própria das ciências, incluindo a investigação, a reflexão, a análise crítica, a imaginação e a criatividade, para investigar causas, elaborar e testar hipóteses, formular e resolver problemas e criar soluções (inclusive tecnológicas), com base nos conhecimentos das diferentes áreas.

Também foi apresentado aos alunos, a ideia do acaso em situações do cotidiano e como se pode descrever o espaço amostral, através de frases que se encaixavam no contexto. No exemplo da moeda ser jogada para cima e cair, todos concordaram que isso aconteceria, mas somente alguns perceberam que cair cara ou coroa era aleatório. 0 primeiro a chegar a essa conclusão foi 0 aluno com TDAH, onde, em sua fala, disse "É aleatório saber se é cara ou coroa!".

Já com a possibilidade de chover hoje, todos concordaram que isso ocorreria, pois o céu seria um sinal de chuva, o celular tem informação do tempo além da própria televisão. Com a afirmação "É possível que meu time ganhe o próximo jogo.", inicialmente, todos acharam que era possível, depois colocando algumas situações, como: o preparo do outro time, a conservação do campo, o clima, entenderam que seria imprevisível, sendo muito aleatório, pois dependia de outros fatores.

No segundo encontro, foi realizada a atividade do jogo dos dados. No primeiro momento, foram apresentados 3 dados, conforme Figura 6 . 0 objetivo foi que os alunos compreendessem a lei de formação da disposição dos números nas faces dos dados, por exemplo, os números 2 e 5 estão em faces opostas dos dados e sua soma será 07 , isto ocorre também com as outras faces. Essa demonstração também permitiu que a geometria pudesse ser discutida com os alunos, comentando sobre as faces e arestas dos dados, lembrando e relacionando com as figuras: reta, quadrado e cubo.

Figura 6 - Modelo de dados construídos para explicar a atividade "Jogo dos Dados".

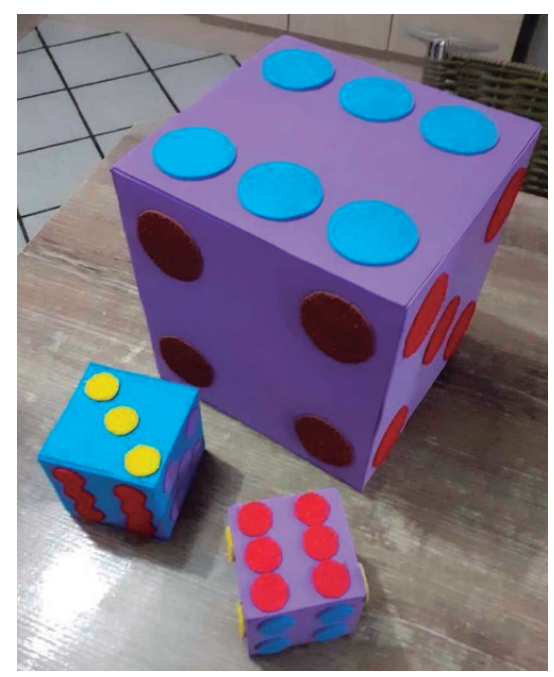

Fonte: Próprio autor. 
A turma foi dividida em grupos e foram entregues, para cada grupo, 3 dados pequenos e a Tabela 1 para ser preenchida. 0 primeiro desafio, com apenas um dado, foi encontrar o número 7 (sete) ao lançar o dado. Foi dado 1 minuto para que os grupos chegassem às suas conclusões, mas rapidamente entre o barulho do dado e entusiasmo dos alunos, ouviam-se as palavras: não é possível, nenhuma possibilidade, não tem como.

0 próximo passo era obter 0 número sete utilizando dois dados. Para essa atividade, foi dado um tempo de 10 minutos, de modo que os alunos encontrassem as possibilidades. Somente um grupo percebeu que $1+6$ e $6+1$ são duas possibilidades, os outros grupos somente associavam uma formação: $1+6,2+5$ e $3+4$. Nesse momento, foi abordada a propriedade comutativa da adição, ainda não vista pelos alunos, mas que facilitou a compreensão de que a soma das parcelas não altera o resultado desejado. Sendo assim, os grupos chegaram à conclusão de que teriam 6 possibilidades.

Para determinar as possibilidades do número sete, agora com os três dados, os grupos entenderam o desafio, mas acharam mais difícil descobrir as formações dos dados, especialmente as possibilidades com os dados em posições diferentes. Apesar da dificuldade, os grupos foram estimulados a testarem suas próprias ideias e a anotarem na tabela. Obviamente esta atividade iria demorar mais, foi proposto um tempo de 20 minutos. A Figura 7 exemplifica um dos momentos de interação com a turma, no caso a construção da atividade com o lançamento dos 3 dados.

Figura 7 - Momento de interação entre os alunos durante 0 lançamento dos 03 dados.

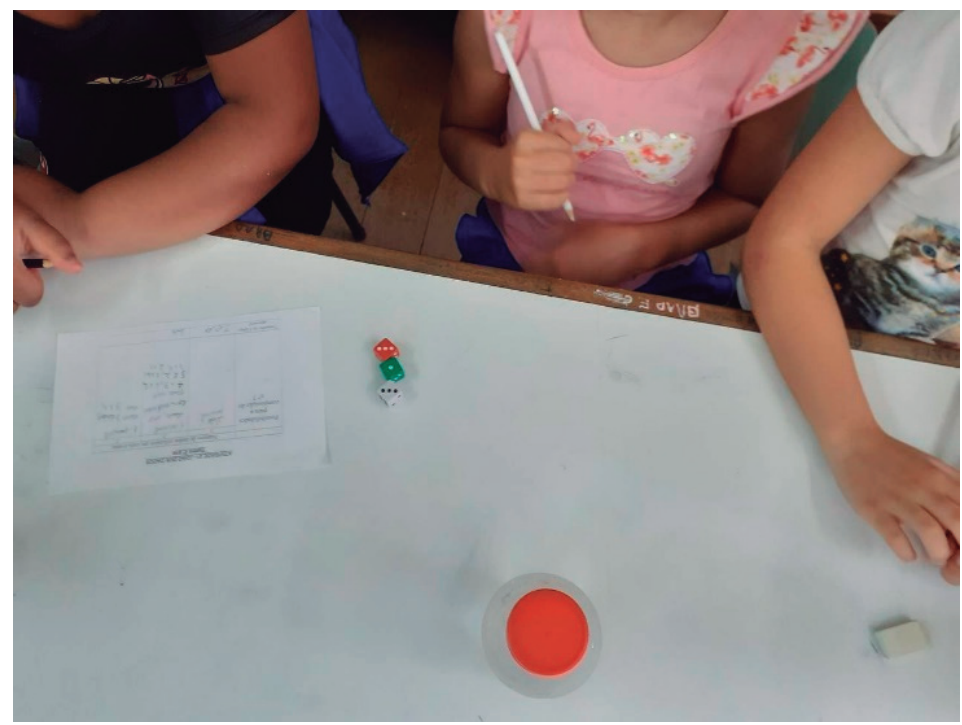

Fonte: Próprio autor.

Não foi possível terminar a atividade no período determinado, pois a grande maioria dos grupos não conseguiu criar todas as possibilidades de formação do número sete, a partir dos 03 dados. Somente 0 grupo que, inicialmente, já havia compreendido o processo de formação com dois dados, conseguiu um número maior de possibilidades de formação. A Figura 8 ilustra a situação. Dessa forma, foi proposto, como tarefa para casa, que os grupos buscassem calcular todas as possibilidades possíveis e, no próximo encontro, iríamos discutir suas respostas. 
Figura 8 - Número de possibilidades, ao lançar os dados, pelo grupo 1.

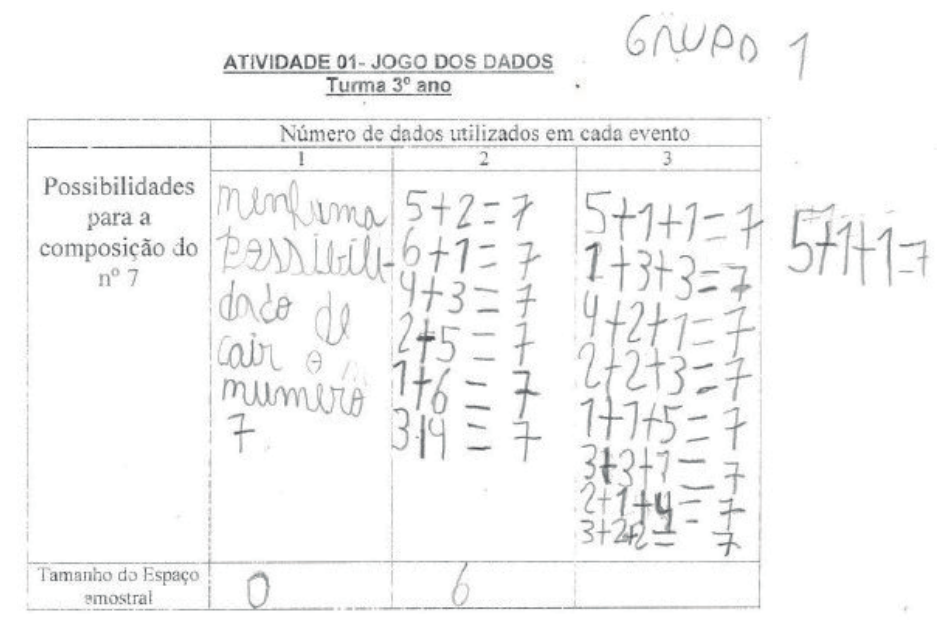

Fonte: Acervo do autor.

No terceiro encontro, começamos com a atividade dos dados para poder concluí-la, destacando, com os alunos, as 15 possibilidades encontradas quando temos 3 dados. Em função da organização das atividades já previstas pela docente da turma e das atividades previstas na escola, optou-se por não construir o gráfico da atividade 01 com os alunos, passando para a $2^{\mathrm{a}}$ atividade, com a aplicação do questionário "Do que você tem medo?".

Os alunos foram divididos novamente em grupos e cada estudante recebeu o questionário, conforme retrata a Figura 2, para a realização da atividade. A Figura 9 ilustra esse momento da atividade. Individualmente, os alunos foram preenchendo e se posicionando frente às perguntas.

Com os questionários respondidos, o grupo começou a tabular suas respostas separando inicialmente por gênero (menina e menino) e, então, organizando por sim (com medo) e não (indiferente). Foi um momento bastante importante, pois a comunicação, o trabalho em equipe, as argumentações estavam muito presentes durante essa proposta. A Figura 10 ilustra esse momento de diálogo que contempla as competências descritas na BNCC (BRASIL, 2017).

Figura 9 - Momento de avaliar os medos individualmente

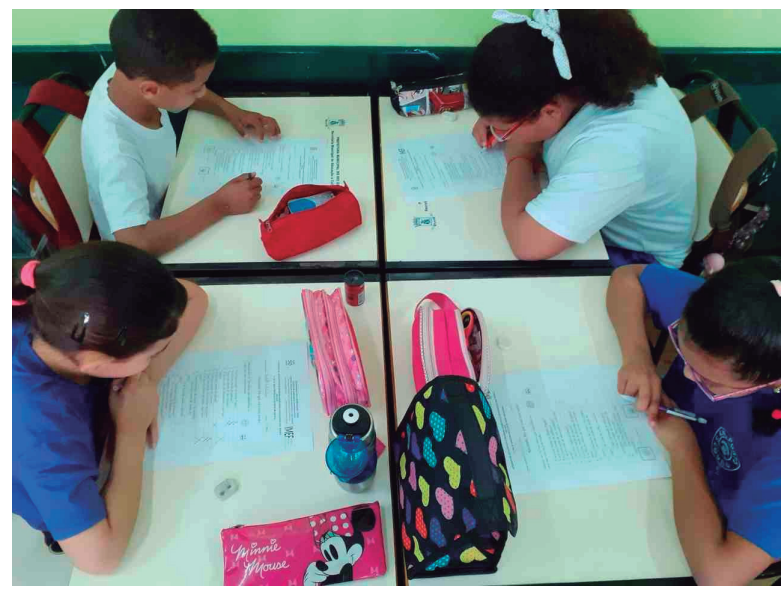

Fonte: Próprio autor. 
Figura 10 - Tabulação do resultado do questionário pelo grupo.

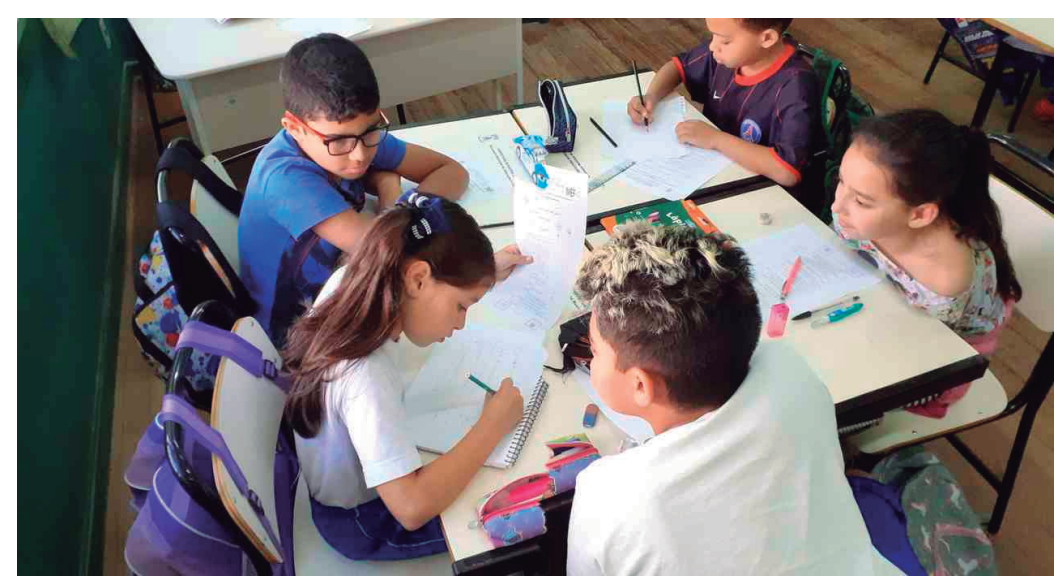

Fonte: Próprio autor.

Com a tabulação de cada grupo, essas informações precisavam ser tabuladas numa única tabela. Para essa atividade, foi utilizado o recurso do quadro da sala de aula e a cada pergunta, um representante informava o resultado do seu grupo até, finalmente, termos todos os dados (variáveis) tabulados. A Figura 11 representa a tabela, construída no quadro, onde foram compiladas as variáveis extraídas do questionário dessa atividade.

Figura 11 - Tabela de compilação de todas as variáveis.

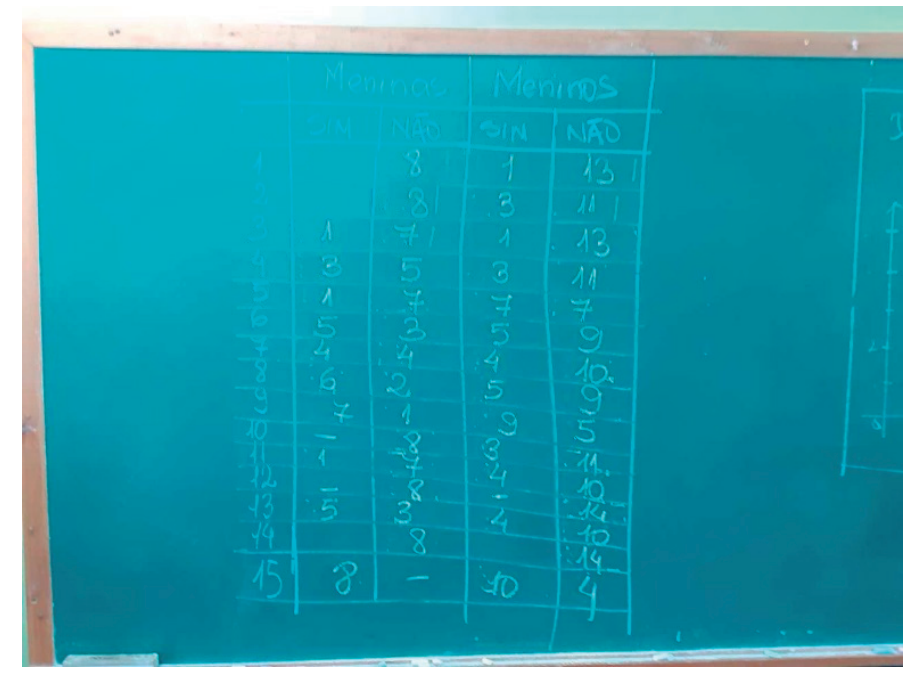

Fonte: Próprio autor.

Com a tabela compilada, chegou o momento de converter os registros tabelados em registros gráficos. Vale lembrar o que diz Colombo et al. (2009), a linguagem discursiva não oferece as mesmas 
possibilidades que podem oferecer uma figura ou um diagrama, respectivamente. Portanto, saímos do hipotético, do imaginário para a visualização concreta de dados através das imagens gráficas.

A integração da estatística com o contexto, último elemento elencado, consiste no entendimento de que os dados, observados sob a perspectiva dos conceitos estatísticos, pertencem a um contexto, e conhecê-lo é fundamental para a compreensão dos significados neles impressos. Pensar sobre esses dados, relacionando-os com o contexto que os gerou, possibilitará fazer juízos, perceber implicações e realizar conjecturas (WILD; PFANNKUSH, $1999^{8}$ apud LOPES \& MENDONÇA, 2016, p. 302).

A citação dos autores traduz o quanto é significativo o uso de Estatística no ensino e aprendizagem não só na disciplina de matemática, mas em todas as áreas de conhecimento, pois como já citado nesse artigo, a Estatística e a Probabilidade transitam em vários ambientes. Situações reais, inseridas nessa proposta numa atividade lúdica, provocam, nos alunos, a busca por respostas aos dados encontrados.

0 próximo momento de interação passa a ser a conversão dos registros tabulados em registros gráficos conforme descreve Duval (2003) e, da mesma forma, em grupos, os alunos iniciam 0 processo de construção. Lembrando que, nesse momento, foram trabalhados a questão da escala, 0 uso da tabuada como recurso e a posição dos eixos, relacionando com a posição horizontal e vertical da reta. A Figura 12 evidencia o momento de construção dos gráficos. Para facilitar a sua construção, também foi necessário um ajuste na proposta da atividade. Os gráficos foram separados em dois títulos: "De que você tem medo? Resposta: Não" e "De que você tem medo? Resposta: Sim". A Figura 13 ilustra os dois tipos de gráficos construídos pela turma.

Figura 12 - Processo de construção dos gráficos

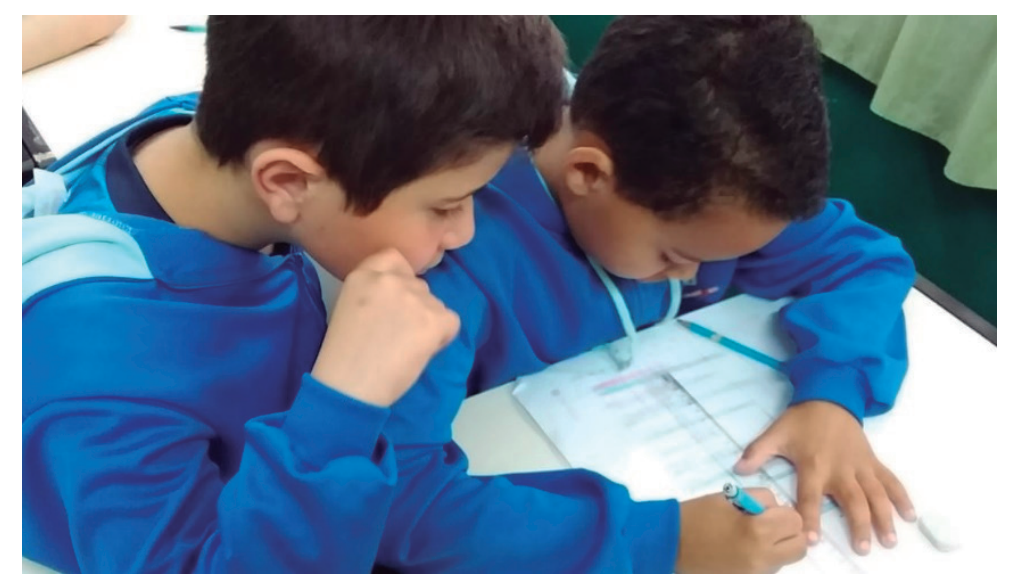

Fonte: Próprio autor.

8 WILD, Chris; PFANNKUCH, Maxine. Statistical thinking in empirical enquiry. International Statistics Review, Malden/MA, v. 67, n. 3, p. 223-265, 1999. 
Figura 13 - Gráficos construídos pelos alunos

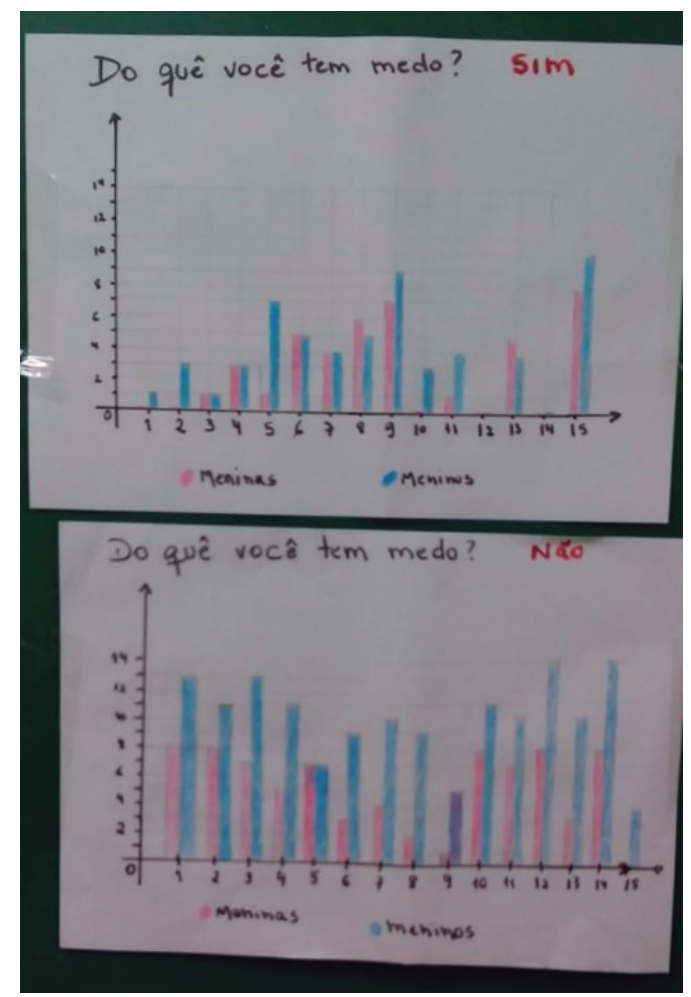

Fonte: Próprio autor.

Ao término da $2^{\mathrm{a}}$ atividade, foi possível perceber muitas das competências desenvolvidas e dos objetivos alcançados propostos pela BNCC (BRASIL, 2017). Na realização dessa atividade, os alunos utilizaram o objetivo de realizar pesquisa envolvendo variáveis categóricas, em um universo de até 50 elementos, organizando os dados coletados utilizando listas, tabelas simples ou de dupla entrada e representando em gráficos de coluna simples, com e sem uso de tecnologias digitais. Nessa situação, as variáveis já haviam sido previamente escolhidas através do questionário.

Ao longo desses três encontros com a turma, a docente regente sempre se fez presente na realização das atividades, evidenciando o quanto era significativo a sua intervenção. Quando questionada de como viu a possibilidade dos alunos, através das atividades, trabalharem um assunto tão distante do conteúdo proposto e, ao mesmo tempo, tão próximo da realidade, a mesma traz o seguinte relato "Creio que foi muito importante eles terem contato com o conteúdo tão além de suas expectativas e ao mesmo tempo tão próximo de suas realidades. Eles ficaram muito surpresos, assim como eu, com a construção e o raciocínio a que chegaram ao final dos gráficos. Foi muito empolgante!"

\section{CONSIDERAÇÕES FINAIS}

As atividades realizadas nos três encontros com a turma do $3^{\circ}$ ano dos Anos Iniciais do Ensino Fundamental, em uma Escola Municipal, atingiram o seu objetivo ao instigar a ideia do acaso em situações do cotidiano vivenciado pelos alunos. Foi possível mostrar o conceito de espaço amostral com a dinâmica do jogo dos dados e a atividade " Do que você tem medo?" além de permitir a coleta, 
leitura, interpretação, classificação e representação de dados e variáveis em tabelas de dupla entrada e em gráficos, permitiu aos alunos o entendimento de como as mesmas variáveis podem ser descritas de formas distintas, conforme descreve Colombo et al. (2009). Ao avaliar os conhecimentos compartilhados nos três encontros, é possível perceber o quanto os alunos apropriaram-se de conceitos tais como: população, amostra, espaço amostral e ideia do acaso através das atividades propostas, reforçando os conhecimentos adquiridos através da construção dos gráficos de colunas.

Pode-se perceber o surgimento e o desenvolvimento de algumas competências como prevê a BNCC (BRASIL, 2017), tais como: a valorização do conhecimento já construído pelo aluno e o que foi promovido com a participação nas atividades; 0 exercício do pensamento científico, da criticidade e da criatividade; 0 processo de comunicação durante a realização das atividades com os seus pares e com 0 grande grupo e o poder de argumentar, com base nos dados e fatos extraídos através das atividades. A autonomia também surgiu em alguns alunos, mostrando o quanto possuem responsabilidade e determinação de forma individual e coletiva, além da empatia e cooperação a partir das atividades, respeitando a cultura de cada um, valorizando a diversidade sem preconceitos.

Com a conclusão das atividades, fica claro o quanto é necessário e urgente o ensino da unidade temática Probabilidade e Estatística no Ensino Fundamental, como era proposto em Brasil (1997) e reafirmado pela BNCC (BRASIL, 2017). Esse conteúdo transita por todas as áreas de conhecimento, dando significado e importância do seu ensino de forma interdisciplinar e transversal.

Da mesma forma, a decisão na estratégia para trabalhar o conteúdo vai depender dos recursos disponíveis na escola, do conhecimento do docente e da aceitação da turma. Segundo Freitas et al. (2019) existem duas dimensões de ausência que podem inferir sobre o trabalho proposto e o que propõe a BNCC (BRASIL, 2017). A primeira delas é o material, pois a demanda pelo uso de tecnologia, de inovação e de projetos sustenta-se na possibilidade de ter computadores e acesso a conexões de internet, já a segunda, está na formação dos professores. Portanto, o desafio ainda está em como os docentes, principalmente os dos Anos Iniciais, estão preparados para desenvolver esse conhecimento matemático num universo de letramento e alfabetização matemática, além dos recursos disponíveis na escola.

0 trabalho dá significado à importância dos conceitos de Estatística e Probabilidade já nos Anos Iniciais, especialmente em como o lúdico pode favorecer essa aprendizagem, ficando como sugestão ao pedagogo, a inserção de outras atividades e jogos lúdicos para abordar essa unidade temática. Como a atividade ocorreu na forma de intervenção nessa turma específica, é importante o docente perceber 0 quanto teve significado essa aprendizagem ao longo das atividades propostas por ele também.

Como um observador implicado na realização das atividades propostas nesses três encontros foi possível perceber 0 quanto os alunos sentiram-se desafiados e instigados em aprender um conteúdo novo, principalmente quando esse conteúdo tem relação com situações cotidianas. A motivação pela descoberta das possibilidades do surgimento do número sete, com o jogo dos dados, promoveu uma explosão de argumentos e respostas, algumas inclusive poderiam ser embasadas em propriedades matemáticas. Com a atividade do questionário, além da interação entre a turma, foi possível perceber o quanto os alunos compreenderam a forma de construção de gráficos, a sua relação com a tabulação inicial dos dados e a surpresa de que podem construir gráficos iguais aos que encontram nos livros didáticos, jornais, entre outros.

0 docente regente, através das atividades, viu a possibilidade dos alunos trabalharem um assunto tão distante do conteúdo proposto e, ao mesmo tempo, tão próximo da realidade, exemplificado pela sua fala: 
Creio que foi muito importante eles terem contato com o conteúdo tão além de suas expectativas e ao mesmo tempo tão próxima de suas realidades. Eles ficaram muito surpresos, assim como eu, com a construção e o raciocínio a que chegaram ao final dos gráficos. Foi muito empolgante! (Docente Regente)

Quando questionado sobre que ações ou atitudes poderiam ocorrer para que o docente se sentisse confortável em trabalhar com a unidade temática Probabilidade e Estatística, sugeriu a realização de oficinas para o conteúdo específico, participação em formações continuadas que promovam 0 estudo da BNCC para aprofundar o conhecimento, e assim, criarem estratégias para que o conteúdo seja prazeroso e tenha aplicações em situações-problemas do cotidiano do aluno.

Com relação ao grau de importância que dão ao letramento matemático, especialmente com relação aos conceitos estatísticos, já descrito segundo Brasil (1997) e revisitado pela BNCC (BRASIL, 2017), considera muito importante que alunos saibam raciocinar e utilizar os conceitos, representações e índices estatísticos para descrever, explicar e predizer fenômenos e situações do cotidiano.

Finalmente, foi possível perceber que o uso do lúdico como ferramenta no processo de ensino e aprendizagem, desperta o interesse nesse conteúdo tão distante e, ao mesmo tempo, tão próximo do cotidiano dos alunos, contribuindo para ampliar a visão do que é matemática.

\section{REFERÊNCIAS}

ABDA, A.B. de Déficit de A. Transtorno do Déficit de Atenção com Hiperatividade. Brasil: [s.n.], 2018. Disponível em: https://tdah.org.br/sobre-tdah/o-que-e-tdah/. Acesso em: 28 out. 2019.

BRASIL, Base Nacional Comum Curricular. Brasília. 598 p. 2017. Disponível em: http://basenacionalcomum.mec.gov.br/. Acesso em: 02 jul. 2019.

BRASIL, Parâmetros Curriculares Nacionais: primeiro e segundo ciclos: Matemática. Brasília. 142 p. 1997. Disponível em: https://bit.ly/3jgwwuq. Acesso em: 12 jul. 2019.

CAZORLA, Irene M.; MAGINA, Sandra M. P.; GITIRANA, Veronica; GUIMARÃES, Gilda L. Estatística para os Anos Iniciais do Ensino Fundamental. SBEM - Sociedade Brasileira de Educação Matemática - Brasília - DF.2017, 121 f.

COLOMBO, Janecler A. A.; BUEHRING, Roberta S.; MORETTI, Méricles T. Registros de representação semiótica, tarefas e análise de dados: articulações em torno do currículo de matemática. REVEMAT - Revista Eletrônica de Educação Matemática - UFSC, Florianópolis, v. 4, n. 1, p. 90-113, 2009.

DUVAL, Raymond. Registros de representações semióticos e funcionamento cognitivo da compreensão em matemática. São Paulo: Papirus, 2003.

FREITAS, Fabrício M.; BERTOLUCCI, Cristina C.; ROVEDA, Crislaine de A.; SILVA, João A. da. Abrindo a Caixa de Pandora: as competências da Matemática na BNCC. RPEM - Revista Paranaense de Educação Matemática - Campo Mourão, PR, v. 8, n. 17, p. 265-291, 2019.

FREITAS, Fabrício M.; SILVA, João A. da; ROVEDA, Crislaine de A.; MARQUES, Paola R. Entre o oficial e o realizado: os currículos prescritos e em ação na Matemática do Ciclo de Alfabetização. RELACult - Revista Latino-Americana de Estudos em Cultura e Sociedade - v. 04, Ed. Especial, Artigo nº 789, p. 1-8, 2018. 
JUNIOR, W. A. A influência da informática no desenvolvimento infantil. Canal do Educador, 2012. Disponível em: https://bit.ly/31pU2PC. Acesso em: 21 nov. 2019.

LOPES, Celi E. A educação estocástica na infância. REVEDUC - Revista Eletrônica de Educação - UFSCAR, São Carlos, v. 6, n. 1, p. 160-174, 2012.

LOPES, Celi E. \& MENDONÇA, Luzinete de 0. Prospectivas para o estudo da Probabilidade e da Estatística no Ensino Fundamental. Revista Eletrônica Vidya - UFN, Santa Maria, v. 36, n. 2, p. 293-314, 2016.

MORGADO, Augusto C.; CARVALHO, Paulo C. P. Matemática Discreta. Rio de Janeiro. Sociedade Brasileira de Matemática/SBEM - Coleção PROFMAT. 2015.

NADAL, Paula. 0 que são os Transtornos Globais do Desenvolvimento (TGD)? Revista Nova Escola, 2011. Disponível em: https://bit.ly/37obec3. Acesso em: 28.out.2019.

PIMENTA, Tatiane. Síndrome de Asperger - Características, diagnóstico e tratamento. Brasil:[s.n.], 2018. Disponível em: https://bit.ly/3m3eKN2. Acesso em: 28. out. 2019.

SANTOS, Gisele A. dos. Tabela simples e de dupla entrada. Plano de aula de matemática para $03^{\circ}$ ano. Revista Nova Escola, 2018. Disponível em: https://bit.ly/34gUcKI. Acesso em: 12 dez. 2019.

RECEBIDO EM: 21 jun. 2020

CONCLUÍDO EM: 03 ago. 2020 
